\author{
碘催化的串联氧化环化反应合成多取代咪唑 \\ 张百群常峰王强张帅查正根汪志勇* \\ (合肥微尺度物质科学国家实验室(筹) 中国科学技术大学软物质化学重点实验室 中国科学技术大学化学系 \\ 合肥 230026)
}

\begin{abstract}
摘要 以苯乙醛和芐胺衍生物为原料, 分子碘作为催化剂, 过氧叔丁醇作为氧化剂合成了一系列的多取代咪坐. 同时 对反应过程中催化剂的用量、氧化剂、溶剂和温度进行了优化, 得到如下最优反应条件: 0.3 equiv. 的分子碘作为催化剂, 过氧叔丁醇作为氧化剂, 乙腈作为溶剂, 反应温度为 $70{ }^{\circ} \mathrm{C}$. 而苯乙酮和苄胺上的吸电子基团均有利于此氧化反应, 对 反应机理也进行了探索性研究并有了较明确的认识. 与传统的咪唑合成方法相比, 该新方法反应条件更温和, 原材料 更易获得.
\end{abstract}

关键词 无金属; 碘催化; 串联氧化环化; 杂环合成; 多取代咪唑

\title{
A Rapid and Efficient Access to Polysubstituted Imidazoles via Iodine-Catalyzed Tandem Oxidative Cyclization
}

\author{
Zhang, Baiqun Wan, Changfeng Wang, Qiang \\ Zhang, Shuai Zha, Zhenggen Wang, Zhiyong* \\ (Hefei National Laboratory for Physical Sciences at Microscale, CAS Key Laboratory of Soft Matter Chemistry and Depart- \\ ment of Chemistry, University of Science and Technology of China, Hefei 230026)
}

\begin{abstract}
Imidazoles represent one of the most important heterocycles which are known to exhibit a wide range of biological and medical activity. Existing methodologies for the synthesis of imidazoles are limited to the generality and accessibility of substrates, and the harsh reaction conditions. The development of milder and more practical protocols should be still desirable and necessary. Here we report a new method for the synthesis of polysubstituted imidazoles. A series of imidazoles was obtained directly from 2-phenylacetaldehyde or acetophenone derivatives and benzylamine derivatives via a metal-free-catalyzed tandem oxidative cyclization. The reaction was performed under mild conditions with iodine as a catalyst and TBHP as an oxidant. The effect of catalyst loading, oxidants, solvents and temperature on this transformation was investigated. The optimal reaction conditions were as follows: 0.3 equiv. of iodine as the catalyst, TBHP as the oxidant, acetonitrile as the solvent and the reaction being carried out at $70{ }^{\circ} \mathrm{C}$. Electron-withdrawing group of acetophenone derivatives and benzylamine derivatives benefit the oxidative reaction. Compared with traditional methods, this reaction was conducted under milder conditions with facile starting materials.
\end{abstract}

Keywords metal-free; iodine catalyst; tandem oxidative cyclization; heterocycle synthesis; polysubstituted imidazoles

\section{Introduction}

Imidazoles represent one of the most important heterocycles which are known to exhibit a wide range of biological and medical activity. ${ }^{[1]}$ For example, imidazole rings are the skeleton of a variety of biological and pharmacological compounds, such as angiotensin II inhibitors, anti-inflammatory and anticancer agents. ${ }^{[2]}$ On the other hand, imidazoles are also extensively used as ligands ${ }^{[3]}$ and environmentally friendly ionic solvents. ${ }^{[4]}$ Due to their wide applicability, many methods for preparing imidazoles have been intensively developed. ${ }^{[5]}$ Traditionally, imidazoles was obtained from cyclo-condensation reactions, such as Brederck reaction ${ }^{[6]}$ involving an addition of $\alpha$-diketones and $\alpha$-haloketones to formamide, the cycloaddition of $p$-tosylmethyl-isocyanide with aldimines (van Lausen's TosMIC chemistry). ${ }^{[7]}$ Recently, many other original methodologies have also reported, such as the direct functionalization of imidazoles rings ${ }^{[8]}$ and acid-based multi-component coupling reactions. ${ }^{[9]}$ While these methods often work well, there are some drawbacks and limitations, such as the generality and accessibility of substrates, and the harsh reaction conditions. Therefore, the development of milder and more practical protocols should be still desirable and necessary.

Because of the economic attractiveness and synthetic efficiency, $\mathrm{C}-\mathrm{H}$ functionalization has received much attention recently. ${ }^{[10]}$ For example, some research groups have

\footnotetext{
*E-mail: zwang3@ustc.edu.cn; Fax: 0551-3603185

Received September 11, 2012; published October 29, 2012.

Supporting information for this article is available free of charge via the Internet at http://sioc-journal.cn.

Project supported by the National Natural Science Foundation of China (Nos. J1030412, 20932002, 20972144, 21172205 and 21272222) and the Chinese Ministry of Science and Technology (No. 2010CB912103).

项目受国家自然科学基金(Nos. J1030412, 20932002, 20972144, 21172205, 21272222)和中国科学技术部(No. 2010CB912103)资助.
} 
efficiently constructed the formation of $\mathrm{C}$ - heteroatom and $\mathrm{C}-\mathrm{C}$ bond through catalytic oxidative activation of $\mathrm{C}-$ $\mathrm{H}$ bond using metal and oxidant as catalytic system. ${ }^{[11]}$ Our group have been focusing on the study of heterocycles syntheses. ${ }^{[12]}$ Here we wish to report an efficient method for the synthesis of imidazoles via a dual $\mathrm{sp}^{3} \mathrm{C}-\mathrm{H}$ functionalization under metal-free conditions.

\section{Results and discussion}

\subsection{Optimization of conditions}

Initially, we employed the reaction of benzylamine (1a) with 2-phenylacetaldehyde (2a) as a model reaction. When the reaction was performed with different catalysts in the presence of oxidant tert-butyl hydroperoxide (TBHP, 5 $\mathrm{mol} \cdot \mathrm{L}^{-1}$ in cyclohexane), it was found that molecular iodine was the most efficient catalyst for the reaction, affording the desired product 3a with a yield of $57 \%$ (Table 1, Entry 4). The structure of 3a was confirmed by X-ray crystallographic analysis (Figure 1). ${ }^{[13]}$

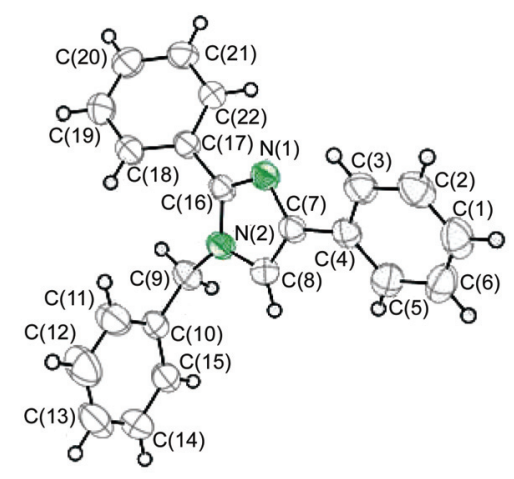

Figure 1 Structure of the $\mathbf{3 a}$ in the crystalline state.

When Lewis acids, ferric chloride and palladium dichloride, were employed as the catalyst respectively, the reaction didn't work at all (Table 1, Entries 2, 3). In the absence of the catalyst, the reaction didn't work either (Table 1, Entry 5). After screening the different iodine loadings, it was found that 0.3 equiv. of iodine should be the best loading while stoichiometric amount of iodine didn't increase the reaction efficiency (Table 1, Entries 4-7). Subsequently, the influence of oxidants on the reaction was investigated. Without oxidant, the reaction was not carried out (Table 1, Entry 8). Among these different oxidants, $t$-BuOOH (TBHP) was the best efficient oxidant for this reaction (Table 1, Entries 9-11). The use of oxidant $m$-CPBA gave the desired product with a very low yield of $21 \%$ while hydrogen peroxide and di-tert-butyl peroxide were useless in this reaction. Besides, solvent had a great influence on this reaction. When the reaction was performed in $\mathrm{C}_{2} \mathrm{H}_{5} \mathrm{OH}, \mathrm{DCE}$, and $\mathrm{DMF}$, the corresponding imidazoles could be obtained with good yields (Table 1 , Entries 12, 13 and 15). When THF was employed as the reaction solvent, no desired product was observed (Table 1, Entry 14). The solvent optimization indicated that $\mathrm{CH}_{3} \mathrm{CN}$ should be the best reaction solvent under the given conditions (Table 1, Entry 6). Finally the temperature effect on the reaction was examined. Only by-product pyrrole derivatives were obtained when the reaction was performed at room temperature (Table 1, Entry 16). Enhancing the reaction temperature also incurred pyrrole derivatives. Therefore the optimal reaction conditions were as follows: 0.3 equiv. of iodine as the catalyst, TBHP as the oxidant, acetonitrile as the solvent and the reaction being carried out at $70{ }^{\circ} \mathrm{C}$.

Table 1 Optimization of the reaction conditions ${ }^{a}$

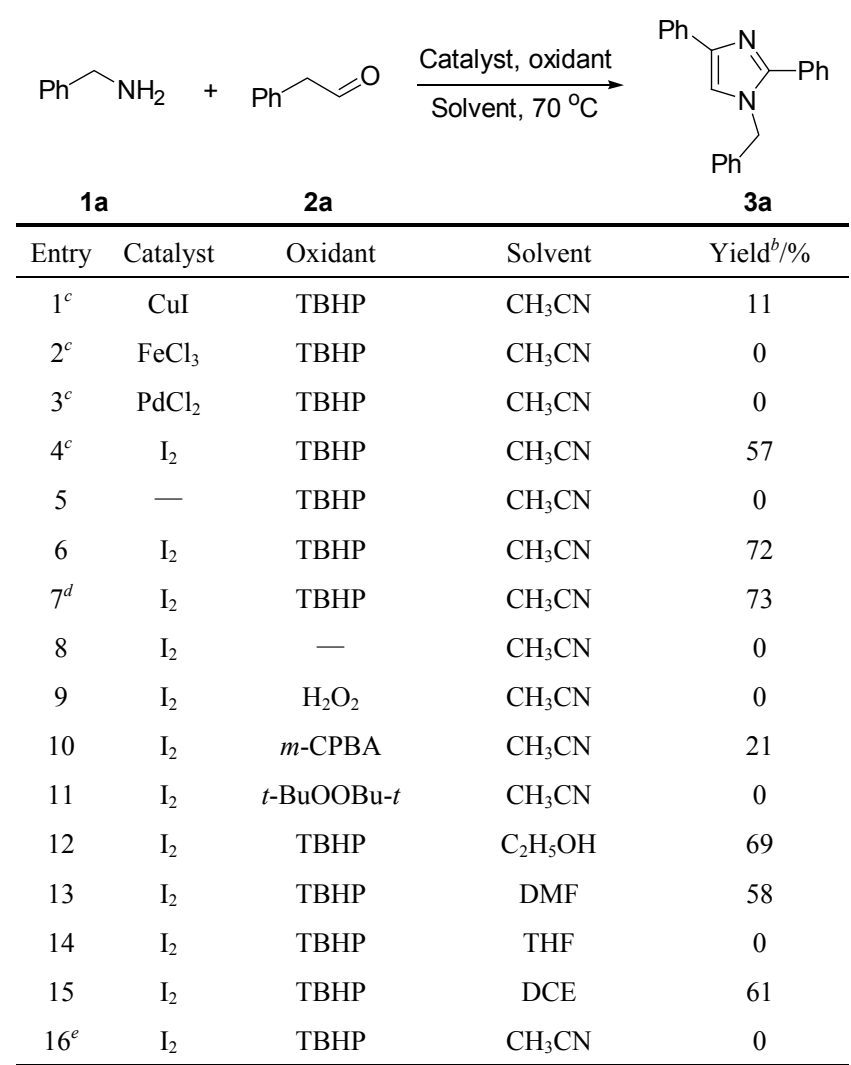

${ }^{a}$ Reaction conditions: 1a (3.0 equiv.), 2a (1.0 equiv., $\left.0.2 \mathrm{mmol}\right)$, catalyst $(0.3$ equiv.), oxidant (2 equiv.), solvent $(1.5 \mathrm{~mL}), 2 \mathrm{~h} ;{ }^{b}$ Isolated yield; ${ }^{c} 10 \mathrm{~mol} \%$ of catalyst; ${ }^{d} 1.0$ equiv. of iodine; ${ }^{e}$ The reaction was carried out at room temperature.

\subsection{Examination the scope of substrates}

With the optimal condition in hand, the scope of substrates was examined under the optimal reaction conditions. Firstly, different benzylamine derivatives were employed as the reaction substrates. Generally, benzylamines bearing electron-withdrawing groups afforded superior yields than those bearing electron- donating groups (Table 2 ). For example, the reaction of (4-methoxyphenyl)methanamine with 2-phenyl- acetaldehyde gave $\mathbf{3 b}$ with a $63 \%$ yield, while the (4-fluorophenyl)methanamine gave the imidazole $3 \mathbf{i}$ with a yield of $73 \%$. The reaction was also applicable to the simply functionalized allylic amines. For instance, $(E)$-2-phenylethenamine reacted with 2-phenylacetaldehyde to give $\mathbf{3 k}$ with a good yield. Heterocycle benzylamine could be a good substrate in this reaction, giving the corresponding product 31 in $51 \%$ yield. However, when 1-phenylethanamine was reacted with $\mathbf{2 a}$, the reaction afforded a pyrrole derivative $\mathbf{3 m}$ instead of a imidazole derivative. It was possible that the reaction proceeded in another process ${ }^{14]}$ since the $\alpha$-position of the amine was occupied by a substituent. When the aliphatic amine was employed as a reaction substrate, it failed to 
produce the desired product. This implied that weaker $\mathrm{C}$ $\mathrm{H}$ bond at $\alpha$-position of benzylamine was necessary for this annulation.

Table 2 Reaction of different benzylamine derivatives with 2-phenylacetaldehyde ${ }^{a}$

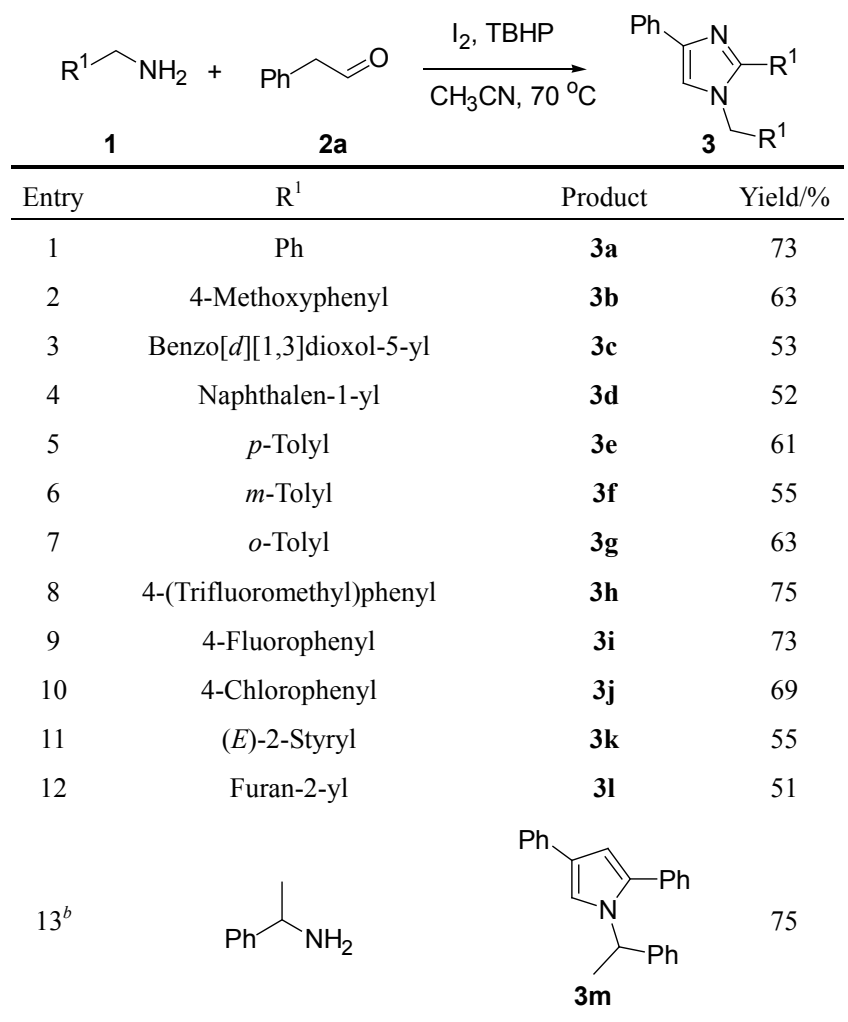

${ }^{a}$ Reaction conditions: 1 (3.0 equiv.), 2 a (1.0 equiv., $\left.0.5 \mathrm{mmol}\right), \mathrm{I}_{2}$ ( 0.3 equiv.), TBHP (2 equiv.), $\mathrm{CH}_{3} \mathrm{CN}(3 \mathrm{~mL}), 2 \mathrm{~h}$. Isolated yield was given; ${ }^{b}$ 1-phenylethanamine as reactant.

Subsequently, we examined the generality of acetophenone derivatives as the reaction substrates. It was found that the reaction also afforded the imidazole derivatives with moderate to good yields (Table 3). The substitution effect on aromatic ring of acetophenone had a great influence on the reaction. The substitution effect of electron-rich groups reduced the reaction yields while electron-poor substituents could favor the reaction (Table 3, 3q, 3r, 3s). For example, the acetophenone bearing a para-nitro group afforded the desired products with a yield of $75 \%$ (Table 3, 3t). Steric effects affected this reaction remarkably. When chloro substituent moved from para-position to ortho-position, the corresponding yield was decreased from $83 \%$ to $58 \%$ (Table 3, 3q and 3u).

As an insight into the mechanism, we performed several control experiments (see the supporting information). When the mixture of phenylacetaldehyde or acetophenone, and tert-butylamine was stirred under the standard conditions, 2-oxo-2-phenylacetaldehyde (A) was obtained. Then we prepared this 2-oxo-2-phenyl-acetaldehyde and employed it as a reaction substrate instead of 2-phenylacetaldehyde, the reaction afforded the imidazole with a yield of 58\%. According to our experimental results and previous report, ${ }^{[12]}$ a possible mechanism was proposed (Scheme 1). Firstly, the iodination of phenylacetaldehyde
Table 3 Reaction of benzylamine with different acetophenone derivatives $^{a}$

$$
\underset{1 \mathrm{a}}{\mathrm{Ph}} \widehat{\mathrm{NH}}_{2}+\underset{\mathrm{R}_{2}}{\stackrel{\mathrm{I}}{\mathrm{CH}_{3} \mathrm{CN}, 70^{\circ} \mathrm{C}}}
$$

\begin{tabular}{cccc}
\hline Entry & $\mathrm{R}^{2}$ & Product & Yield/\% \\
\hline 1 & $\mathrm{Ph}$ & $\mathbf{3 n}$ & 61 \\
2 & $m$-Tolyl & $\mathbf{3 o}$ & 52 \\
3 & $p$-Tolyl & $\mathbf{3 p}$ & 65 \\
4 & 4-Chlorophenyl & $\mathbf{3 q}$ & 83 \\
5 & 4-Fluorophenyl & $\mathbf{3 r}$ & 73 \\
6 & 4-(Trifluoromethyl)phenyl & $\mathbf{3 s}$ & 80 \\
7 & 4-Nitrophenyl & $\mathbf{3 t}$ & 75 \\
8 & 2-Chlorophenyl & $\mathbf{3 u}$ & 58 \\
9 & 2-Fluorophenyl & $\mathbf{3 v}$ & 53 \\
10 & 2-Bromophenyl & $\mathbf{3 w}$ & 60 \\
\hline
\end{tabular}

${ }^{a}$ Reaction conditions: 1a (4.0 equiv), $\mathbf{2}(1.0$ equiv, $0.2 \mathrm{mmol}), \mathrm{I}_{2}$ ( 0.3 equiv.), TBHP (3 equiv.), $\mathrm{CH}_{3} \mathrm{CN}(1.5 \mathrm{~mL}$ ). Isolated yield was given.

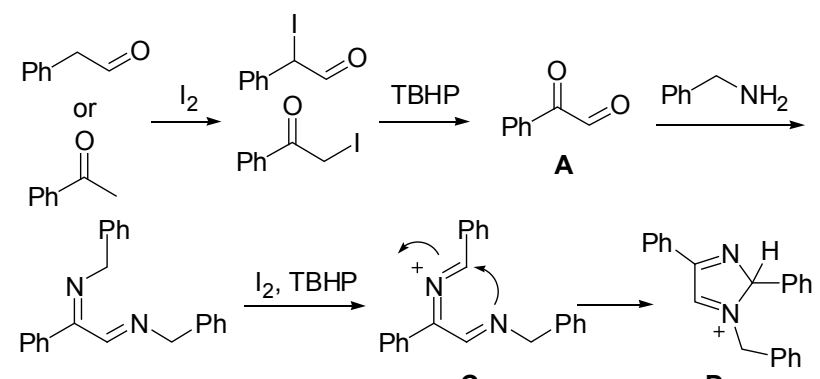

B

C

D<smiles>C[I+](C)c1cn(Cc2ccccc2)c(-c2ccccc2)n1</smiles>

Scheme 1 A tentative mechanism for the reaction.

or acetophenone forms 2-iodo-2-phenylacetaldehyde or 2-iodo-1-phenyl-ethanone. ${ }^{[15]}$ Then the corresponding iodide was oxidized to $\mathbf{A}^{[15]}$ followed by the condensation with benzylamine to give the imine $\mathbf{B}$. This imine $\mathbf{B}$ could be oxidized into imine cation $\mathbf{C}$ in the presence of iodine and TBHP. ${ }^{[16]}$ Then intermediate $\mathbf{D}$ was formed via an intramolecular cyclization. After deprotonation the target product was obtained.

\section{Conclusion}

In summary, we developed an efficient method for the synthesis of imidazoles via a dual $\mathrm{sp}^{3} \mathrm{C}-\mathrm{H}$ functionalization under metal-free conditions. With catalytic amount of iodine as catalyst and TBHP as oxidant, a consecutive oxidation-cyclization was realized to afford a series of imidazoles with good yields under mild condition. The reaction mechanism was investigated and the application of this alternative synthesis of imidazoles is in progress in our laboratory. 


\section{References}

[1] (a) Rizzi, J. P.; Nagel, A. A.; Rosen, T.; Mclean, S.; Seeger, T. J. Med. Chem. 1990, 33, 2721; (b) Sarshar, S.; Zhang, C.; Moran, E. J.; Krane, S.; Rodarte, J. C.; Benbatoul, K. D.; Dixon, R.; Mjalli, A. M. M. Bioorg. Med. Chem. 2000, 10, 2599.

[2] (a) Atwell, G. A.; Fan, J.-Y.; Tan, K.; Denny, W. A. J. Med. Chem. 1998, 41, 4744; (b) Carunu, D. J.; Duncia, J. V.; Johnson, A. L.; Chiu, A. T.; Price, W. A.; Wong, P. C.; Timmermans, P. J. Med. Chem. 1990, 33, 1330; (c) Messina, F.; Botta, M.; Corelli, F.; Schneider, M. P.; Fazio, F. J. Org. Chem. 1999, 64, 3767; (d) Khanna, I. K.; Weier, R. M.; Yu, Y.; Xu, X. D.; Koszyk, F. J.; Collins, P. W.; Koboldt, C. M.; Veenhuizen, A. W.; Perkins, W. E.; Casler, J. J.; Masferrer, J. L.; Zhang, Y. Y.; Gregory, S. A.; Seibert, K.; Isakson, P. C. J. Med. Chem. 1997, 40, 1634.

[3] (a) Garrison, J. C.; Youngs, W. J. Chem. Rev. 2005, 105, 3978; (b) Braband, H.; Kueckmann, T.; Theresa, I.; Abram, U. J. Organomet. Chem. 2005, 690, 5421; (c) Scott, N. M.; Nolan, S. P. Eur. J. Inorg. Chem. 2005, 1815; (d) Enders, D.; Niemeier, O.; Henseler, A. Chem. Rev. 2007, 107, 5606; (e) Bourissou, D.; Guerret, O.; Gabbai, F. P.; Bertrand, G. Chem. Rev. 2000, 100, 39; (f) Arnold, P. L.; Liddle, S. T. Chem. Commun. 2006, 3959.

[4] (a) Dupont, J.; Souza, R. F. d.; Suarez, P. A. Z. Chem. Rev. 2002, 102, 3667; (b) Nara, S. J.; Naik, P. U.; Harjani, J. R.; Salunkhe, M. M. Indian J. Chem. 2006, 45, 2257; (c) Chowdhury, S.; Mohan, R. S.; Scott, J. L. Tetrahedron 2007, 63, 2363.

[5] (a) Kamijo, S.; Yamamoto, Y. Chem.-Asian J. 2007, 2, 568; (b) Delest, B.; Nshimyumukiza, P.; Fasbender, O.; Tinant, B.; Brynaert, J. M.; Darro, F.; Robiette, R. J. Org. Chem. 2008, 73, 6816; (c) Kison, C.; Opatz, T. Chem.-Eur. J. 2009, 15, 843; (d) Horneff, T.; Chuprakov, S.; Chernyak, N.; Gevorgyan, V.; Fokin, V. V. J. Am. Chem. Soc. 2008, 130, 14972; (e) Kanazawa, C.; Kamijo, S.; Yamamoto, Y. J. Am. Chem. Soc. 2006, 128, 10662; (f) Giles, R. L.; Sullivan, J. D.; Steiner, A. M.; Looper, R. E. Angew. Chem., Int. Ed. 2009, 48, 3116; (g) Zhong, Y.-L.; Lee, J.; Reamer, R. A.; Askin, D. Org. Lett. 2004, 6, 929; (h) Giles, R. L.; Nkansah, R. A.; Looper, R. E. J. Org. Chem. 2010, 75, 261.

[6] Bredereck, H.; Theilig, G. Chem. Ber. 1953, 86, 88.

[7] (a) Salvatori, M. D. R. S.; Abou-Jneid, R.; Ghoulami, S.; Martin, M.-T.; Zaparucha, A.; Al-Mourabit, A. J. Org. Chem. 2005, 70, 8208; (b) Gwiazda, M.; Reissig, H. U. Synlett 2006, 1683; (c) Zhong, Y.-L.; Lee, J.; Reamer, R. A.; Askin, D. Org. Lett. 2004, 6, 929; (d) Sisko, J.; Kassick, A. J.; Mellinger, M.; Filan, J. J.; Allen, A.; Olsen, M. A. J. Org. Chem. 2000, 65, 1516.
[8] (a) Collman, J. P.; Zhong, M.; Zhang, C.; Costanzo, S. J. Org. Chem. 2001, 66, 7892; (b) Altman, R. A.; Buchwald, S. L. Org. Lett. 2006, 8, 2779; (c) Cristau, H. J.; Cellier, P. P.; Spindler, J. F.; Taillefer, M. Chem.-Eur. J. 2004, 10, 5607; (d) Liu, L.; Frohn, M.; Xi, N.; Dominguez, C.; Hungate, R.; Reider, P. J. J. Org. Chem. 2005, 70, 10135; (e) Lv, X.; Wang, Z.; Bao, W. Tetrahedron 2006, 62, 4756; (f) Collman, J. P.; Zhong, M. Org. Lett. 2000, 2, 1233; (g) Lan, J.-B.; Chen, L.; Yu, X.-Q.; You, J.-S.; Xie, R.-G. Chem. Commun. 2004, 188; (h) Kantam, M. L.; Venkanna, G. T.; Sridhar, C.; Sreedhar, B.; Choudary, B. M. J. Org. Chem. 2006, 71, 9522.

[9] (a) Sharma, S. D.; Hazarika, P.; Konwar, D. Tetrahedron Lett. 2008, 49, 2216; (b) Kidwai, M.; Mothsra, P. Tetrahedron Lett. 2006, 47 5029; (c) Wolkenberg, S. E.; Wisnoski, D. D.; Leister, W. H.; Wang, Y.; Zhao, Z.-J.; Lindsley, C. W. Org. Lett. 2004, 6, 1453; (d) Usyatinsky, A. Y.; Khmelnitsky, Y. L. Tetrahedron Lett. 2000, 41, 5031.

[10] (a) Li, Y.-Z.; Li, B.-J.; Lu, X.-Y.; Lin, S.; Shi, Z.-J. Angew. Chem., Int. Ed. 2009, 48, 3817; (b) Borduas, N.; Powell, D. A. J. Org. Chem. 2008, 73, 7822; (c) Wang, L.; Fu, H.; Jiang, Y.-Y.; Zhao, Y.-F. Chem.-Eur. J. 2008, 14, 10722; (d) Boldron, C.; Gamez, P.; Tooke, D. M.; Spek, A. L.; Reedijk, J. Angew. Chem., Int. Ed. 2005 44, 3585; (e) Jiang, H.; Huang, H.; Cao, H.; Qi, C. Org. Lett. 2010, 12,5561 .

[11] Li, C.-J. Acc. Chem. Res. 2009, 42, 335.

[12] (a) Yan, Y.; Wang, Z. Chem. Commun. 2011, 47, 9513; (b) Wang, Q.; Wan, C.; Gu, Y.; Zhang, J.; Gao, L.; Wang, Z. Green Chem. 2011, 13, 578; (c) Zhang, J.-T.; Yu, C.-M.; Wang, S.-J.; Wan, C.-F.; Wang, Z.-Y. Chem. Commun. 2010, 46, 5244; (d) Zhang, J.; Zhu, D.; Yu, C.; Wan, C.; Wang, Z. Org. Lett. 2010, 12, 2841; (e) Wan, C.; Zhang, J.; Wang, S.; Fan, J.; Wang, Z. Org. Lett. 2010, 12, 2338; (f) Wan, C.; Gao, L.; Wang, Q.; Zhang, J.; Wang, Z. Org. Lett. 2010, 12,3902 .

[13] CCDC 900085 (3a) contains the supplementary crystallographic data for this paper. These data can be obtained free of charge from the Cambridge Crystallographic Data Centre via www.ccdc.cam.ac. uk/data_request/.

[14] (a) Li, Q.; Fan, A.; Lu, Z.; Cui, Y.; Lin, W.; Jia, Y. Org. Lett. 2010 12, 4066; (b) Wan, X.; Xing, D.; Fang, Z.; Li, B.; Zhao, F.; Zhang, K.; Yang, L.; Shi, Z. J. Am. Chem. Soc. 2006, 128, 12046.

[15] (a) Wei, W.; Shao, Y.; Hu, H.; Zhang, F.; Zhang, C.; Xu, Y.; Wan, X. J. Org. Chem. 2012, 77, 7157; (b) Jiang, H.; Huang, H.; Cao, H.; Qi, C. Org. Lett. 2010, 12, 5561; (c) Lamani, M.; Prabhu, K. R. Chem.-Eur. J. 2012, 18, 14638; (d) Zhang, X.; Wang, L. Green Chem. 2012, 14, 2141.

[16] Yan, Y.; Zhang, Y.; Feng, C.; Zha, Z.; Wang, Z. Angew. Chem., Int. Ed. 2012, 51, 8079.

(Zhao, C.) 